\title{
MiR-25-3p Serves as an Oncogenic MicroRNA by Downregulating the Expression of Merlin in Osteosarcoma
}

This article was published in the following Dove Press journal: Cancer Management and Research

\author{
Hua-chun Raol,* \\ Zhao-ke Wu ${ }^{1, *}$ \\ Si-da Wei ${ }^{\prime}$ \\ Yun Jiang' \\ Qing-xin Guo' \\ Jia-wen Wang' \\ Chang-xian Chen' \\ Hui-yong Yang ${ }^{2}$ \\ 'Quanzhou Orthopedic-Traumatological \\ Hospital, Fengze District, Quanzhou, \\ Fujian, People's Republic of China; \\ ${ }^{2}$ School of Medicine, Institute of \\ Molecular Medicine, Huaqiao University, \\ Quanzhou, People's Republic of China \\ *These authors contributed equally to \\ this work.
}

Purpose: Moesin-ezrin-radixin-like protein (Merlin) has been identified as a tumor suppressor in several types of cancers. However, the biological function of Merlin in osteosarcoma remains unclear. MicroRNAs (miRNAs) can influence cancer progression by targeting oncogenes or anti-oncogenes. In this study, we sought to evaluate the regulation of Merlin expression by miR-25-3p and the role of the miR-25-3p/Merlin axis in osteosarcoma progression, with the aim of identifying a potential therapeutic target for osteosarcoma.

Materials and Methods: TCGA (The Cancer Genome Atlas) database was used to analyze the correlation between Merlin expression and prognosis. RT-qPCR and Western blotting analyses were performed to compare Merlin expression between normal and malignant cells. A dual-luciferase reporter assay was performed to evaluate the direct targeting of Merlin by miR-25-3p. We overexpressed miR-25-3p, or/and Merlin, in U-2 OS and 143B cells, and studied their cellular functions in vitro. MTT and colony formation assays were performed to determine the effects on cell growth. EdU and cell cycle assays were performed to analyze the effects in cell replication. We used annexin V-fluorescein isothiocyanate and propidium iodide to stain apoptotic cells, and analyzed the cells using flow cytometry. The effects on cell metastasis were studied in wound healing and transwell assays. Lastly, the underlying mechanism was determined in RT-qPCR and Western blotting experiments.

Results: Low Merlin expression was linked to poor prognosis. miR-25-3p was observed to directly target Merlin and downregulate its expression. miR-25-3p promoted cell growth, migration, and invasion, and inhibited apoptosis induced by cisplatin. Moreover, the overexpression of Merlin reversed the abovementioned effects of miR-25-3p. Further, the miR25-3p/Merlin axis was observed to play an important role in the Hippo pathway, and regulated the expression of genes such as BIRC5, CTGF, and CYR61.

Conclusion: miR-25-3p functions as an oncogenic microRNA in osteosarcoma by targeting Merlin, and may serve as a potential therapeutic target for osteosarcoma.

Keywords: Merlin, miR-25-3p, osteosarcoma, proliferation, apoptosis, metastasis

\section{Introduction}

As one of the most commonly occurring primary malignant bone tumors, osteosarcoma (OS) accounts for over $10 \%$ of all solid tumors. ${ }^{1-3}$ OS primarily affects young individuals, and is the second leading cause of cancer-associated mortality in children and adolescents worldwide. $^{4,5}$ The 5-year overall survival rate of OS has increased to approximately $6070 \%$ owing to the considerable advances in surgical technologies and combined therapeutic strategies. ${ }^{6}$ However, the survival rate remains poor in patients at advanced
Correspondence: Chang-xian Chen

Tel $+86|36369| 3|| 2$

Email ccx6070@qq.com

Hui-yong Yang

Tel +8615359531722

Email shyhy@hqu.edu.cn 
clinical stages and with pulmonary metastases. ${ }^{7}$ Therefore, it is necessary to explore novel drugs or therapeutic strategies for OS treatment.

Merlin, a 70-kDa protein, is encoded by NF2. It belongs to the ezrin, radixin, and moesin (ERM) protein family, the members of which share a homologous domain that contains an $\alpha$-helical central domain, a C-terminal tail, and an N-terminal FERM domain. ${ }^{8}$ In humans, Merlin is primarily expressed in neural tissue; however, it is also expressed in other fetal tissues, and is predominantly detected in adhesion junctions. Loss-of-function mutation or deletion in NF2 often results in neurofibromatosis type 2, a disease marked by the formation of multiple tumors in the nervous system. ${ }^{9}$ Merlin affects growth inhibition, which is inactivated by joint integrin/ receptor tyrosine kinase signaling and activated by intercellular adhesion. ${ }^{10}$ Several studies have shown that Merlin plays the role of a tumor suppressor in certain types of cancers, such as prostate cancer and melanoma. ${ }^{11-13}$ Based on the abovementioned findings, we hypothesized that Merlin can inhibit OS progression as well.

MicroRNAs (miRNAs) represent a group of endogenous RNA molecules that do not encode proteins. They usually consist of 19-22 nucleotides. MiRNAs can be anti-oncogenic or oncogenic, which depends on the characteristics of the target genes. ${ }^{14-16}$ In recent years, miRNA-targeted therapeutics has emerged as an important anticancer strategy. ${ }^{17}$ Therefore, the identification of miRNAs that play essential roles in cancer progression can be useful. It has been reported that miR-25-3p is expressed at high levels in OS tissues and sera in patients with OS, and its dysregulation correlates negatively with the clinical prognosis. ${ }^{18,19}$ miR-25-3p seems to be an oncogenic miRNA. However, the definite effect of miR-25-3p on the functions of OS cells has not been determined clearly. In this study, we observed that miR-25-3p directly targeted Merlin and downregulated its expression. Accordingly, we hypothesized that miR-25-3p may serve as an oncogenic miRNA in OS by downregulating Merlin expression. To confirm our hypothesis, a series of cellular function experiments were performed in vitro.

The Hippo signaling pathway is an evolutionarily conserved pathway that regulates cell proliferation, apoptosis, and stem cell self-renewal. ${ }^{17}$ Activation of the Hippo pathway can promote antitumor immune responses, and its dysregulation contributes to cancer development. ${ }^{20}$ Yes-associated protein (YAP), which is a transcriptional co-factor, and transcriptional co-activator with PDZ-binding motif (TAZ) are the major downstream proteins of the Hippo signaling pathway. Collectively, they constitute the transcriptional module. Upon entering the nucleus, YAP/TAZ binds to the transcription factor TEAD and upregulates the expression of genes essential to cell proliferation and survival, ${ }^{21}$ including BIRC5, CTGF, and CYR61. ${ }^{22-24}$ Merlin is one of the upstream components of the Hippo pathway. Li et al observed that Merlin binds to DCAF1 in the nucleus to suppress the activity of the E3 ubiquitin ligase CRL4. This consequently inhibits the ubiquitination of LATS1/2 and promotes the phosphorylation of YAP. The phosphorylation of YAP leads to its cytoplasmic retention, spatial separation with transcription factors, and degradation, and results in antitumor activity. ${ }^{25-27}$ Based on the above findings, we also attempted to determine whether miR-25-3p exerts cancer-promoting effects via the Hippo pathway.

In this study, we confirmed the role of miR-25-3p in OS progression and determined the underlying mechanism with an aim to identify a potential candidate for miRNA therapy.

\section{Materials and Methods Bioinformatic Analysis}

Data for Merlin mRNA levels and overall survival time of patients with OS were retrieved from the TARGET database (URL: https://ocg.cancer.gov/programs/target). The data have been presented in Supplemental Table 1. The relationship between Merlin expression levels and survival time was analyzed using Kaplan-Meier analysis.

\section{Cell Cultures}

U-2 OS, 143B, and 293T cells were purchased from ATCC. hFOB1.19, MG-63, and Saos-2 cells were obtained from IMMOCELL (Xiamen, Fujian, China, URL: http://immocell. com/index.html). The negative control and treatment cells were maintained in Dulbecco's modified Eagle medium DMEM (Gibco, Detroit, MI, USA) supplemented with 10\% fetal bovine serum (FBS, Gibco), 2 mM L-glutamine (Gibco), $100 \mathrm{U} / \mathrm{mL}$ penicillin (Gibco), and $100 \mathrm{U} / \mathrm{mL}$ streptomycin (Gibco).

\section{Plasmid Constructs}

The 3' UTR of NF2 was amplified by quantitative real-time polymerase chain reaction (RT-qPCR) using human genomic DNA. The primers used are listed in Table 1. The 3' UTR fragment of NF2 was cloned downstream of the firefly luciferase reporter gene in the pmirGLO vector (Promega, Madison, WI, USA). The mutant version of the Merlin-3'UTR plasmid was constructed using QuikChange II Site-Directed Mutagenesis Kit (Agilent Technologies, CA, USA). 
Table I Primers for Plasmid Constructs

\begin{tabular}{|l|l|}
\hline pmirGLO-Merlin-3'UTR-F & 5'-CTCGCTAGCCTCGAGACCTGCCACTTCTCCTGCTAC-3' \\
\hline pmirGLO-Merlin-3'UTR-R & 5'-ATGCCTGCAGGTCGACCATTTAAGTTATAATCGTTC-3' \\
pmirGLO-Merlin-3'UTR -Mut-F & 5'-TCTTATGCTAGCATGCCTTGAACTACGACCCTG-3' \\
pmirGLO-Merlin-3'UTR -Mut-R: & 5'-CAAGGCATGCTAGCATAAGAGGGGCTGGGCTC-3' \\
Merlin-F & 5'-CTAGAGCTAGCGAATTCATGGCCGGGGCCATCGCTTC-3' \\
Merlin-R & 5'-TCGCGGCCGCGGATCCGAGCTCTTCAAAGAAGGCCAC-3' \\
\hline
\end{tabular}

NF2 was amplified by PCR and cloned into the lentiviral vector $\mathrm{pCDH}-\mathrm{EF} 1-\mathrm{MCS}-\mathrm{Puro}$ for the overexpressing Merlin. The primers used for PCR are listed in Table 1.

\section{Dual-Luciferase Reporter Activity Assay}

293T cells were seeded in a 24-well plate and co-transfected with the mimic control or the miR-25-3p mimic and the pmirGLO-WT Merlin-3'UTR plasmid or the pmirGLOMutant Merlin-3'UTR plasmid after they achieved 6080\% confluence. The following day, the $293 \mathrm{~T}$ cells were lysed and the luciferase activity was measured using the DualLuciferase Reporter Assay System (Promega, Madison, WI, USA) and normalized to Renilla luciferase activity. Each treatment was carried out in triplicate.

\section{Transfection}

The miR-25-3p mimic and the appropriate negative control mimic (mimic NC) were purchased from RiboBio (Guangzhou, Guangdong, China). U-2 OS and 143B cells were seeded in respective 6-well plates. Once the cells reached $6080 \%$ confluence, they were transfected with the miR-25-3p mimic (200 pmol/well) or the mimic NC (200 pmol/well) using Lipofectamine ${ }^{\mathrm{TM}} 2000$ (Invitrogen, Carlsbad, NY, USA). Four micrograms of pCDH-Merlin plasmid was used per well during co-transfection with the miR-25-3p mimic. After transfection for $24 \mathrm{~h}$, the cells were harvested for the subsequent experiments. The transfection efficiency was determined by RT-qPCR and Western blotting.

Table 2 Primers for RT-qPCR Assay

\begin{tabular}{|c|c|}
\hline miR-25-RT & $\begin{array}{l}\text { 5'-GTCGTATCCAGTGCAGGGTCCG } \\
\text { AGGTATTCGCACTGGATACGACTCAGAC-3' }\end{array}$ \\
\hline miR-25-3p-F & 5'- GCGCATTGCACTTGTCTCG-3' \\
\hline miR-25-3p-R & 5'- AGTGCAGGGTCCGAGGTATT-3' \\
\hline U6-RT & 5'-CGCTTCACGAATTTGCGTGTCAT-3' \\
\hline U6-F & 5'-GCTTCGGCAGCACATATACTAAAAT-3' \\
\hline U6-R & 5'-CGCTTCACGAATTTGCGTGTCAT-3' \\
\hline Merlin-F & 5'- TGAACGCACGAGGGATGAGTTG-3' \\
\hline Merlin-R & 5'- GCCTTTTCAGCCAACAGGTCAG-3' \\
\hline BORC5-F & 5'-CCACTGAGAACGAGCCAGACTT-3' \\
\hline BORC5-R & 5'-GTATTACAGGCGTAAGCCACCG-3' \\
\hline CTGF-F & 5'-CTTGCGAAGCTGACCTGGAAGA-3' \\
\hline CTGF-R & 5'-CCGTCGGTACATACTCCACAGA-3' \\
\hline CYR6I-F & 5'-GGAAAAGGCAGCTCACTGAAGC-3' \\
\hline CYR6I-R & 5'-GGAGATACCAGTTCCACAGGTC-3' \\
\hline I8S RNA-F & 5'-CGACGACCCATTCGAACGTCT-3' \\
\hline I8S RNA-R & 5'-CTCTCCGGAATCGAA CCCTGA-3' \\
\hline
\end{tabular}




\section{RT-qPCR Assay}

Total RNA was isolated from the 143B and U-2 OS cells using Total RNA Extraction Reagent (Vazyme, Nanjing, Jiangsu, China). Merlin, BORC5, CTGF, and CYR61 cDNA was synthesized using a HiScript II 1st Strand cDNA Synthesis Kit (Vazyme). MiR-25 was reverse transcribed using a miRNA 1st Strand cDNA Synthesis Kit (Vazyme) according to the instructions of the manufacturer. qPCR was performed using iQ5 Real-Time PCR Detection System (Bio-Rad Laboratories, Hercules, CA, USA) with a ChamQ SYBR qPCR Master Mix kit (Vazyme). The thermocycling conditions were as follows: $95^{\circ} \mathrm{C}$ for $3 \mathrm{~min}$, followed by 45 cycles of $95^{\circ} \mathrm{C}$ for $20 \mathrm{sec}$, $58{ }^{\circ} \mathrm{C}$ for $20 \mathrm{sec}$, and $72{ }^{\circ} \mathrm{C}$ for $20 \mathrm{sec}$. Each detection was performed in triplicate. The primers used in the qPCR experiment are listed in Table 2. The expression levels of Merlin, BORC5, CTGF, and CYR61 were normalized to U6 or 18S rRNA expression levels.

\section{Western Blotting}

143B and U-2 OS cells were lysed using RIPA buffer. The lysates (30 $\mu \mathrm{g} / \mathrm{sample}$ ) were loaded for electrophoresis on $10 \%$ denaturing SDS-PAGE gels, following which they were transferred onto a polyvinylidene difluoride membrane. The membrane was blocked by treating with Tris-HCl buffer containing $5 \%$ bovine serum albumin for $2 \mathrm{~h}$. Following this, the membrane was probed with primary antibodies overnight at $4{ }^{\circ} \mathrm{C}$, washed five times with Tris-HCl buffer, and incubated with secondary antibodies at $28{ }^{\circ} \mathrm{C}$ for $1 \mathrm{~h}$. Next, the membranes were washed for five times and the bands were visualized using a Chemiluminescent Detection Reagent kit (South San Francisco, CA, USA). The following antibodies were used in the study: Merlin (Cat: 21,686-AP, Proteintech, Chicago, IL, USA), YAP (Cat: 14074T, Cell Signaling, Boston, MA, USA), p-YAP (Cat: 13008T, Cell Signaling), GAPDH (Cat: 5174, Cell Signaling), anti-rabbit IgG and HRP-linked antibody (Cat: 7074, Cell Signaling).

\section{EdU Incorporation}

After transfection for $24 \mathrm{~h}$, the U-2 OS and 143B cells were incubated with DMEM containing EdU $(50 \mu \mathrm{m}$, RiboBio) at $37{ }^{\circ} \mathrm{C}$ for $4 \mathrm{~h}$. The cells were fixed with $4 \%$ formaldehyde for $20 \mathrm{~min}$, following which glycine was added and the mixture was maintained $10 \mathrm{~min}$. After treatment with $0.5 \%$ Triton $\mathrm{X}-100$ at $28{ }^{\circ} \mathrm{C}$ and maintenance for $15 \mathrm{~min}$, the cells were washed thrice with PBS. Next, the cells in each well were treated with $200 \mu \mathrm{L}$ of
1X Apollo reaction cocktail for $20 \mathrm{~min}$. Subsequently, nuclear DNA was stained with DAPI $(5 \mu \mathrm{g} / \mathrm{mL})$. The cells were imaged using a fluorescent microscope (MOTIC, Hong Kong, China).

\section{Cell Proliferation Assay}

After transfection for $24 \mathrm{~h}$, the U-2 OS and 143B cells were seeded into 96-well plates at a density of $10^{4}$ cells per well. An MTT assay kit (Cat: QF0025, Qiancheng Biotech, Shanghai, China) was used to evaluate cell viability at each time point according to the manufacturer's instruction. The SpectraMax Absorbance Reader (Molecular Devices, San Francisco, CA, USA) was used to measure the absorbance at $490 \mathrm{~nm}$. The data are represented in terms of mean \pm s.d. for sextuple wells.

\section{Colony Formation Assay}

After transfection for $24 \mathrm{~h}$, the U-2 OS and 143B cells were seeded into 6-well plates at a density of $10^{3}$ cells per well and cultured in DMEM supplemented with $10 \%$ FBS for 1-2 weeks. When the colonies were visible to the naked eye, the cells were fixed with methanol for $20 \mathrm{~min}$. After washing thrice, the colonies were stained with $0.5 \%$ crystal violet in PBS for $20 \mathrm{~min}$. Lastly, the colonies were imaged. The experiments were performed thrice independently, and the numbers of colonies were counted for analysis.

\section{Cell Cycle Assay}

After transfection for $48 \mathrm{~h}$, the U-2 OS and 143B cells were harvested and fixed in $70 \%$ ethanol at $4{ }^{\circ} \mathrm{C}$ overnight. The next day, the cells were washed twice with PBS and incubated with $0.2 \%$ Triton X-100 and $10 \mu \mathrm{g} / \mathrm{mL}$ RNase in PBS at $37^{\circ} \mathrm{C}$ for $30 \mathrm{~min}$. Next, the cells were stained with propidium iodide (PI, $20 \mu \mathrm{g} / \mathrm{mL}$ ) in dark at $28{ }^{\circ} \mathrm{C}$ for 30 min. The stained cells were observed using a flow cytometer NovoCyte (Cat: 1300, ACEA, San Diego, CA, USA). The experiments were performed thrice independently.

\section{Cell Apoptosis Assay}

After transfection for a 24-h period, the U-2 OS and 143B cells were treated with $10 \mu \mathrm{g} / \mathrm{mL}$ cisplatin (Selleck, Shanghai, China) at $37{ }^{\circ} \mathrm{C}$ for $24 \mathrm{~h}$. Next, the cells were harvested and stained with $200 \mu \mathrm{g} / \mathrm{mL}$ Annexin V-fluorescein isothiocyanate (FITC) and $30 \mu \mathrm{g} / \mathrm{mL}$ PI (Cat: A211-02, Vazyme, Nanjing, China) in dark at $28^{\circ}$ $\mathrm{C}$ for $10 \mathrm{~min}$. Immediately afterwards, the fluorescence for $10^{6}$ cells per sample was analyzed using the flow 
cytometer NovoCyte, and the percentage of apoptotic cells were determined. The experiments were performed thrice independently.

\section{Wound Healing Assay}

After transfection for $24 \mathrm{~h}$, the U-2 OS and 143B cells were seeded in 6-well plates. When the cells reached $100 \%$ confluence, a $200 \mu \mathrm{L}$ pipette tip was used to wound the cells by a straight scratch. The cells were sequentially maintained in serum-free DMEM. Wound healing was observed under a microscope (MOTIC).

\section{Transwell Assay}

Transwell plates (Corning, Coring, NY, USA) were used to perform the migration and invasion assays. After transfection for $24 \mathrm{~h}, 2-5 \times 10^{5} \mathrm{U}-2$ OS and $143 \mathrm{~B}$ cells were seeded in the upper chambers. For the invasion assay, the membrane of the upper chamber was pre-coated with 5-fold diluted Matrigel (BD Biosciences, Sparks, MD). The following day, the migrated/invasive cells were fixed with $4 \%$ formaldehyde and stained with $0.5 \%$ toluidine blue. Lastly, the migrated/invasive cells were imaged and counted in three random fields.

\section{Statistical Analysis}

Statistical analyses were performed using SPSS software 22.0 (IBM SPSS, Armonk, NY, USA). Unpaired Student's $t$-test was performed for the pairwise comparison of groups. ANOVA (two-way analysis of variance) was performed to identify significant differences among multiple groups. $p<0.05$ was considered statistically significant.

\section{Results}

\section{Low Expression Levels of Merlin Were Linked to Poor Prognosis}

Studies have shown that Merlin plays the role of a tumor suppressor. $^{11-13}$ To investigate the clinical significance of Merlin in OS, we analyzed the data on the mRNA levels of NF2 in 87 patients with OS retrieved from the TARGET database. The results of the Kaplan-Meier survival analysis showed that patients with low Merlin expression exhibited a shorter OS duration (Figure 1A), which indicates that Merlin may also serve as a tumor suppressor in OS. There were no data corresponding to normal tissues in the TCGA database; therefore, we compared the Merlin expression levels between a normal osteoblast (hFOB1.19) and malignant cells (U-2 OS, 143B, Saos-2, and MG-63). As shown in
Figure 1BD, Merlin was expressed at low levels in malignant cells compared to that in hFOB1.19. Among malignant cells, U-2 OS cells had the lowest expression levels of Merlin, while 143B cells had the highest. Based on the above results, we selected U-2 OS and 143B cells for the subsequent experiments.

\section{MiR-25-3p Binds Directly to the 3' UTR of Merlin and Downregulates the Expression of Merlin}

To identify the potential miRNAs that target Merlin, we performed a search using the TargetScan database and identified hsa-miR-25-3p as a candidate miRNA (Figure 2A). Next, we used a dual-luciferase reporter assay to determine whether miR-25-3p binds directly to the $3^{\prime}$ UTR of Merlin in 293T cells. As shown in Figure 2B, the co-transfection of the miR-25-3p mimic with the pmirGLO-Merlin 3'UTR plasmid significantly inhibited luciferase activity compared to that in the negative control. This could be reversed by a mutation at the miR-25-3p binding site in Merlin 3' UTR (Figure 1B). Furthermore, there were obvious reductions in the mRNA and protein levels of Merlin in U-2 OS and 143B cells after transfection with miR25-3p (Figure 2C and D). The overexpression of Merlin after transfection with the pCDH-Merlin plasmid reversed the reduction in Merlin mRNA and protein levels (Figure 2C and D). Collectively, these data indicate that miR-25-3p directly targets Merlin and downregulates its expression.

\section{MiR-25-3p Promotes Cellular Proliferation}

To confirm the effects of miR-25-3p and Merlin on the growth of OS cells, we first performed an MTT assay to evaluate cell viability. As shown in Figure 3A, miR-25$3 p$ significantly promoted the growth of U-2 OS and 143B cells. Additionally, transfection of the miR-25-3p mimic observably promoted colony formation (Figure $3 \mathrm{~B}$ and $\mathrm{C})$. The number of colonies increased from $207 \pm 10$ to $381 \pm 15(p<0.001)$ for $143 \mathrm{~B}$ cells and from $208 \pm 8$ to $467 \pm 23$ ( $p<0.001)$ for U-2 OS cells. Moreover, the EdU proliferation assay showed that transfection with miR-25-3p increased the percentage of $\mathrm{EdU}^{+}$cells, which were cells in replication (Figure $3 \mathrm{D}$ and E). For $143 \mathrm{~B}$ cells, the percentages were $34.1 \pm$ $1.4 \%$ and $51.6 \pm 3.0 \%(p<0.01)$ in the mimic $\mathrm{NC}$ 
A

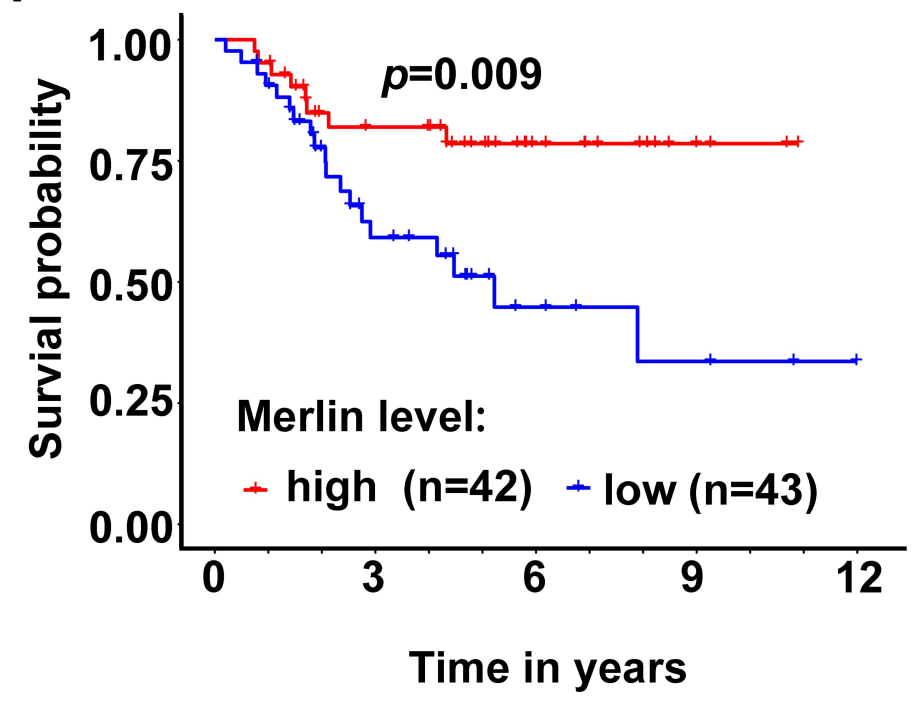

B

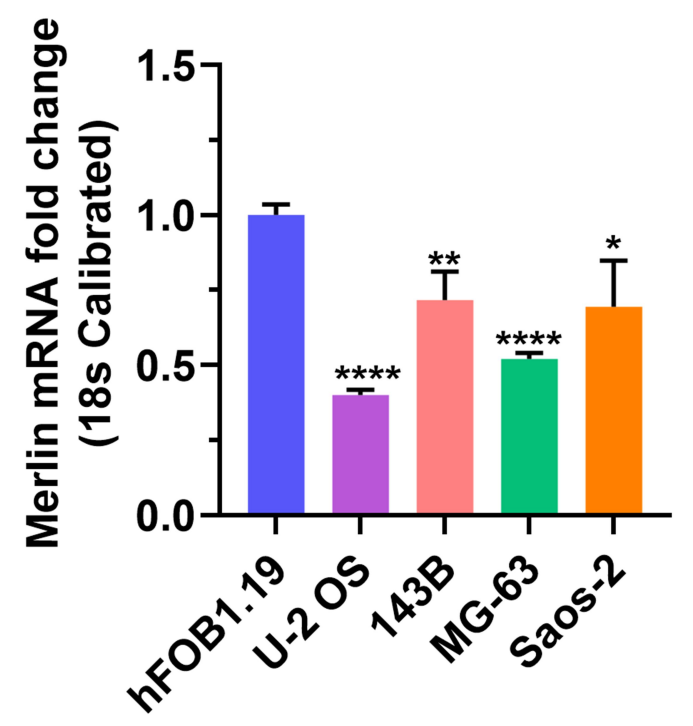

D
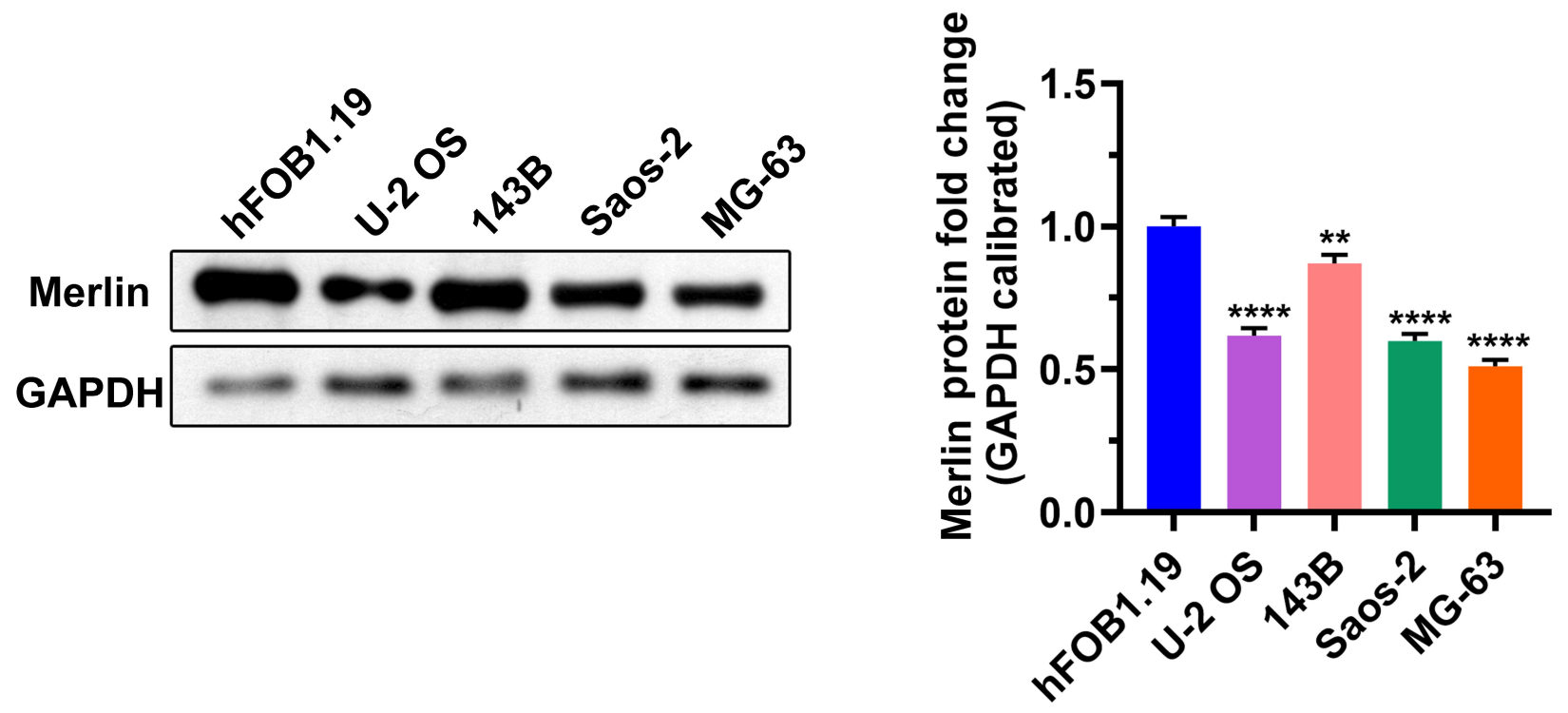

Figure I Low expression of Merlin was linked to poor prognosis in patients with osteosarcoma in the data retrieved from TCGA database. TCGA: The Cancer Genome Atlas. (A) The Kaplan-Meier survival analysis showed that patients with low Merlin expression exhibited a shorter OS time. (B) RT-qPCR analysis of the Merlin expression levels in cells. (C) Representative image of Western blotting analysis. (D) Semiquantitative analysis of Merlin protein levels in cells. The data are expressed in terms of mean \pm s.d. ${ }_{p} p<0.05$, $* * p<0.01$, **** $p<0.000$ I.

group and the miR-25-3p group, respectively. For U-2 OS cells, the percentages were $34.6 \pm 12.6 \%$ and $44.3 \pm$ $0.5 \%(p<0.01)$ in the mimic NC group and the miR25-3p group, respectively. Collectively, these results suggest that miR-25-3p promotes cell growth. The cell cycle assay revealed that miR-25-3p reduced the percentage of cells in the G0/G1 phase (Figure $4 \mathrm{~A}$ and B) from $35.2 \pm 0.8 \%$ to $30.0 \pm 1.1 \%(p<0.01)$ for $143 \mathrm{~B}$ cells and from $45.5 \pm 1.0 \%$ to $29.4 \pm 2.5 \%(p<0.001)$ for U-2 OS cells. These findings indicate that miR-25$3 p$ promotes cell growth by facilitating entry into the $\mathrm{S}$ phase and protecting cells from G0/G1 arrest. In addition, co-transfection of the pCDH-Merlin plasmid with the miR-25-3p mimic reversed the effects of miR25-3p (Figures $3 \mathrm{AE}$ and $4 \mathrm{~A}$ and $\mathrm{B}$ ). In summary, the above data indicates that miR-25-3p promotes the replication of cells by targeting Merlin, and thereby promotes cell growth. 
A

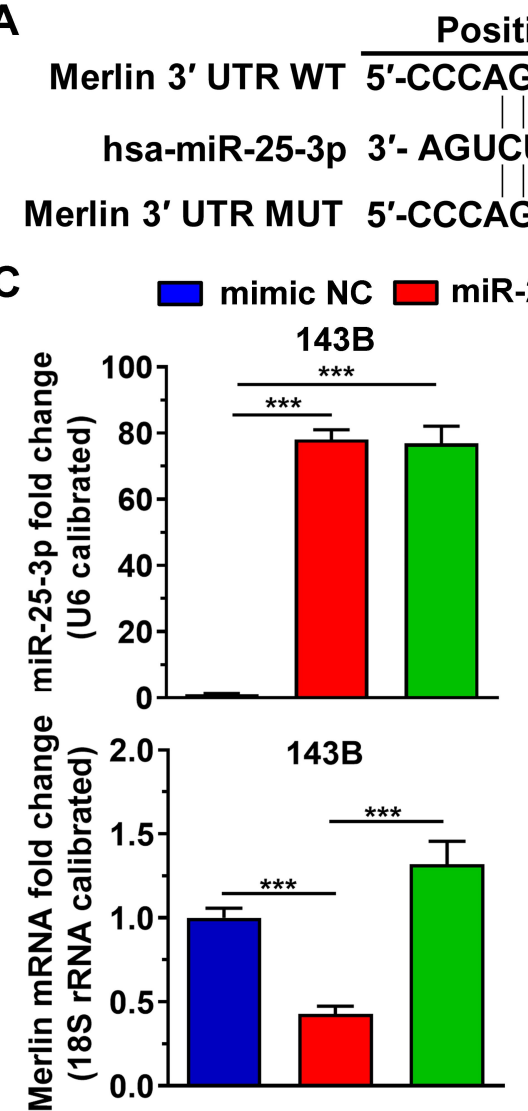

Position 495-518 of Merlin 3' UTR CUGGCUCUGUUCACGUUAC -5' AGCCCUCUUAUGCUAGCAU -3'
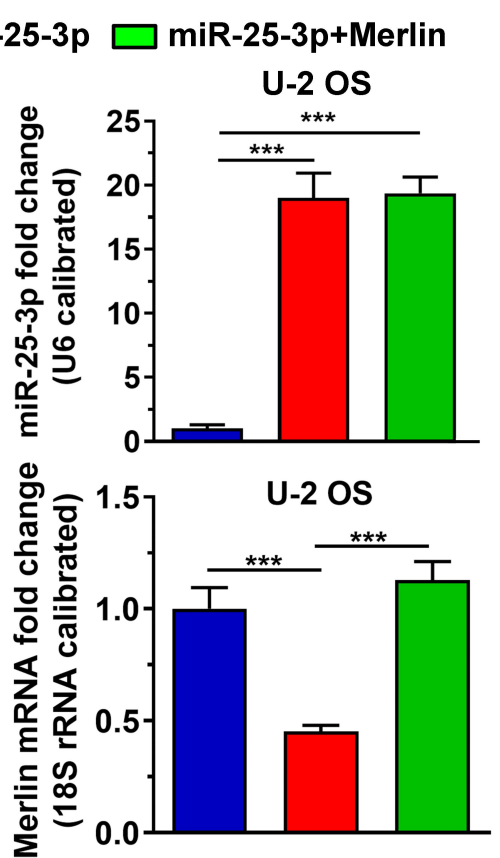

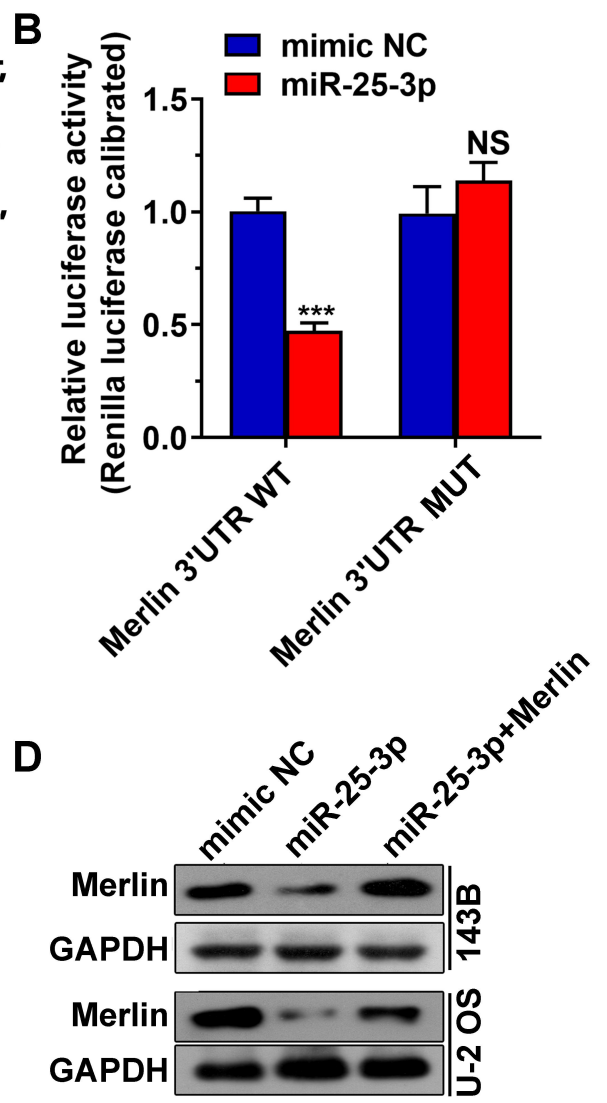

Figure 2 MiR-25-3p targets Merlin directly and downregulates its expression. (A) Merlin 3' UTR targeted by miR-25-3p and its mutant. (B) Dual-luciferase reporter assay indicating that miR-25-3p directly targeted Merlin 3' UTR. (C) RT-qPCR analysis was performed $24 \mathrm{~h}$ after transfection. The results showed that miR-25-3p reduced the Merlin mRNA levels in U-2 OS I43B cells. (D) MiR-25-3p downregulated the protein expression of Merlin in U-2 OS and I43B cells upon transfection for 24 h. The data are expressed in terms of mean \pm s.d. NS: not significant. ${ }^{* * *} p<0.00 \mathrm{I}$.

\section{MiR-25-3p Inhibits Apoptosis Induced by Cisplatin}

Next, we attempted to study the influence of miR-25-3p in apoptosis regulation. We used $10 \mu \mathrm{g} / \mathrm{mL}$ cisplatin to treat 143B and U-2 OS cells after transfection. Annexin V-FITC and PI were used to stain the apoptotic cells. As shown in Figure $4 \mathrm{C}$ and $\mathrm{D}$, transfection with miR-25-3p reduced the percentage of apoptotic cells from $24.5 \pm 2.0 \%$ to $15.1 \pm$ $1.1 \%(p<0.01)$ for $143 \mathrm{~B}$ cells and from $14.0 \pm 0.2 \%$ to $7.8 \pm 0.9 \%(p<0.001)$ for U-2 OS cells, both reductions being significant. Moreover, the co-overexpression of Merlin reversed the reduction induced by miR-25-3p (Figure 4C and D). These results suggest that miR-25-3p inhibits cellular apoptosis induced by cisplatin by targeting Merlin.

\section{MiR-25-3p Improves Metastasis}

To investigate the effect of miR-25-3p on cell migration, we performed the wound healing assay as well as the transwell cell migration assay. As shown in Figure 5A, transfection of the miR-25-3p mimic significantly promoted the migration of U-2 OS and 143B cells. The number of migrated cells in the miR-25a-3p group were observably higher than that in the mimic $\mathrm{NC}$ group (Figure 5B and C). Moreover, miR-25-3p also increased the number of invasive cells (Figure 5D and E), which indicates that miR-25-3p promoted invasion by U-2 OS and 143B cells. In addition, co-overexpression of Merlin reversed the miR-25-3p-induced inhibition of migration and invasion. These data indicate that miR-25-3p/Merlin signaling plays an essential role in promoting metastasis.

\section{MiR-25-3p Promotes Cell Growth and Inhibits Apoptosis via the Hippo Pathway The Hippo pathway is a conserved signaling pathway involved in the control of cell growth and apoptosis, ${ }^{28-30}$ and YAP phosphorylation acts as a negative signal for it. ${ }^{27}$}


A

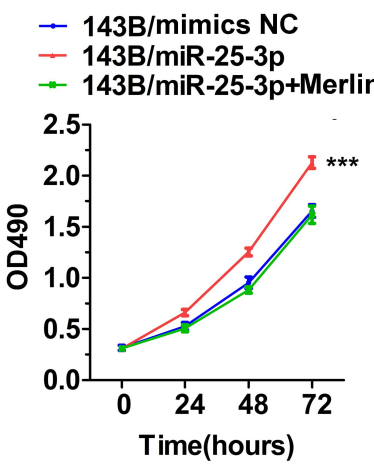

- U-2 OS/mimic NC

- U-2 OS/miR-25-3p

* U-2 OS/miR-25-3p+ Merlin

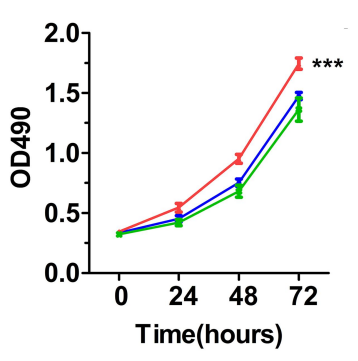

B

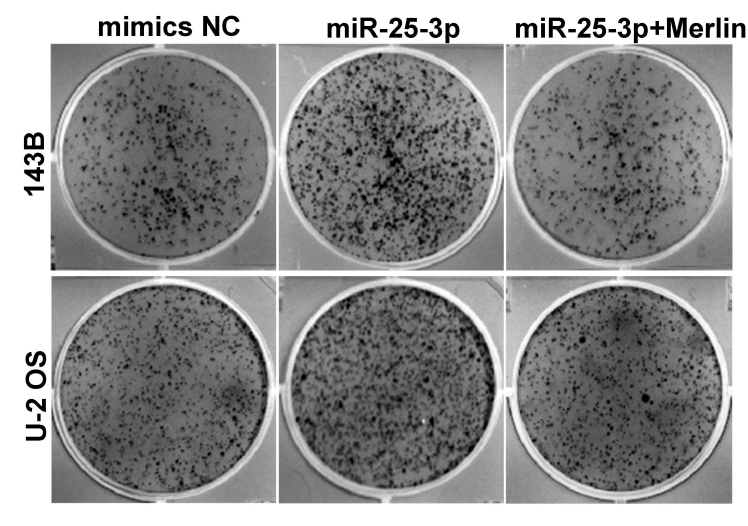

C

C 143B
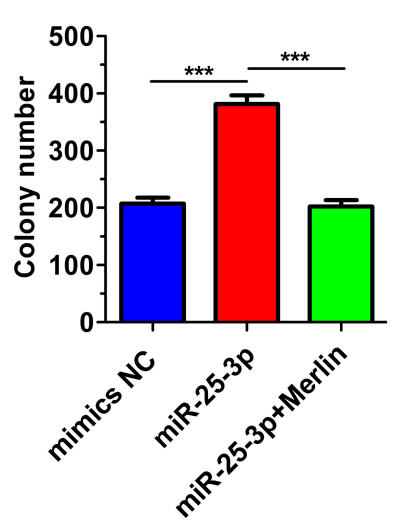

U-2 os
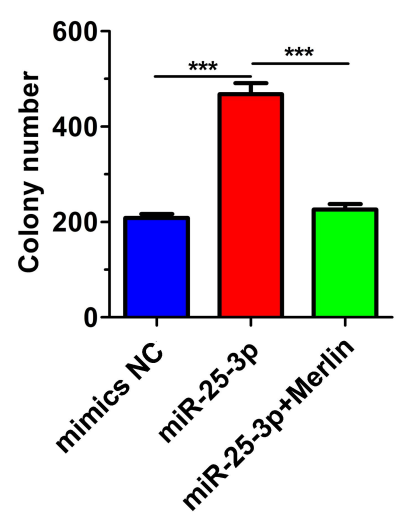

D

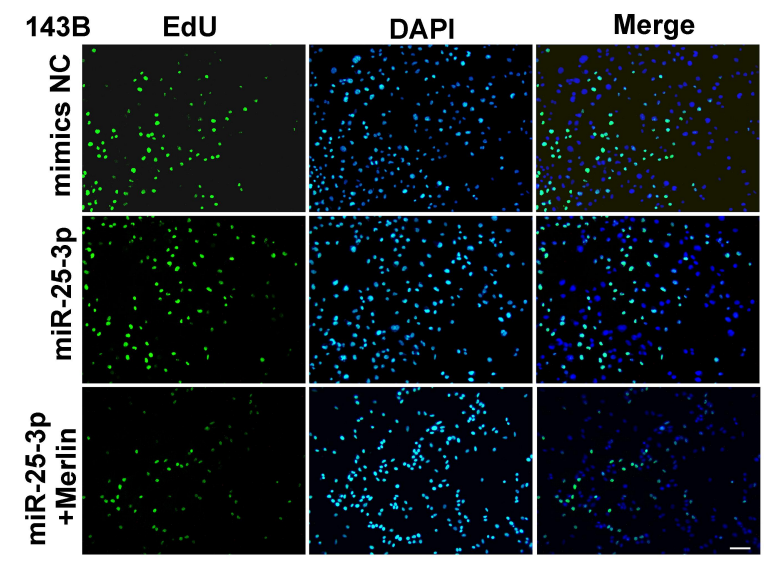

U-2 OS EdU

DAPI
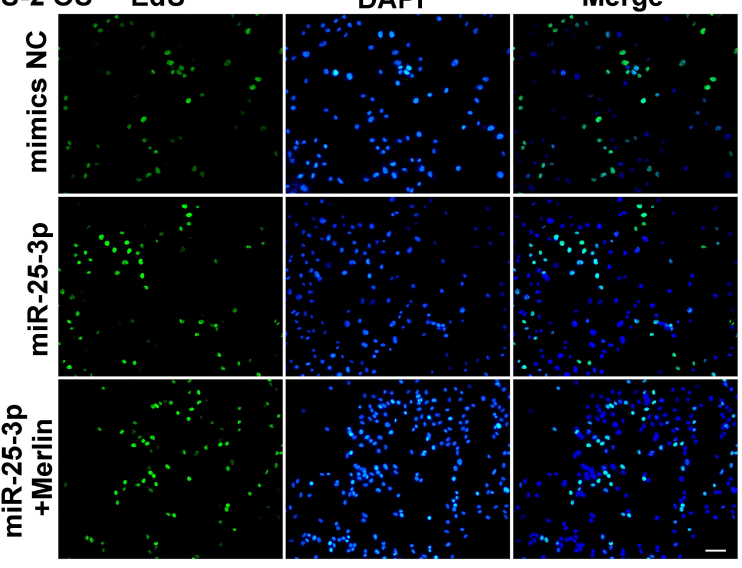

E

143B
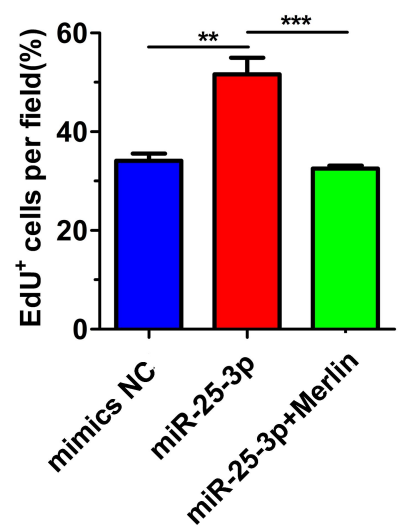

U-2 OS
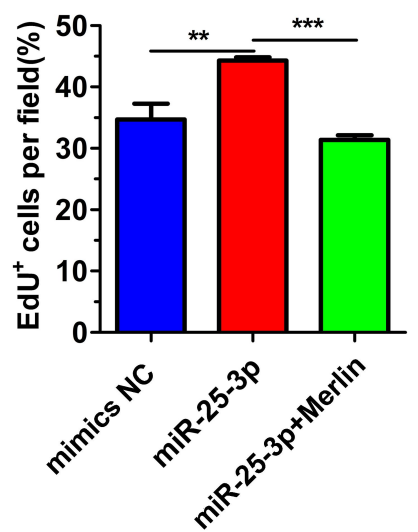

Figure 3 MiR-25-3p promotes cell growth. (A) MTT assay of osteosarcomatous cells demonstrated that miR-25-3p promotes cell growth, and that Merlin reversed this effect. (B) Representative images of cell colony formation assay. (C) Histogram of the colony numbers $(n=3)$. (D) Representative images of the EdU proliferation assay. Bars, $100 \mu \mathrm{m}$. (E) Quantification of EdU+ cells $(n=3)$. The data are expressed in terms of mean \pm s.d. $* * p<0.01$, $* * * p<0.00 \mathrm{I}$.

Merlin is an upstream component of the Hippo pathway. ${ }^{26}$ We investigated the regulatory effects of miR-25-3p on the molecules downstream of Merlin. As shown in Figure 6A, miR-25-3p suppressed the phosphorylation of YAP. Moreover, the mRNA expression levels of several YAPtargeting genes, such as BIRC5, CTGF, and CYR61, ${ }^{22}$ were upregulated after transfection with the miR-25-3p mimic (Figure 6B). In addition, the reduction in phosphorylation and increase in mRNA levels were reversed upon the co-overexpression of Merlin. The above findings suggest that miR-25-3p regulates the Hippo pathway by targeting Merlin. 
A
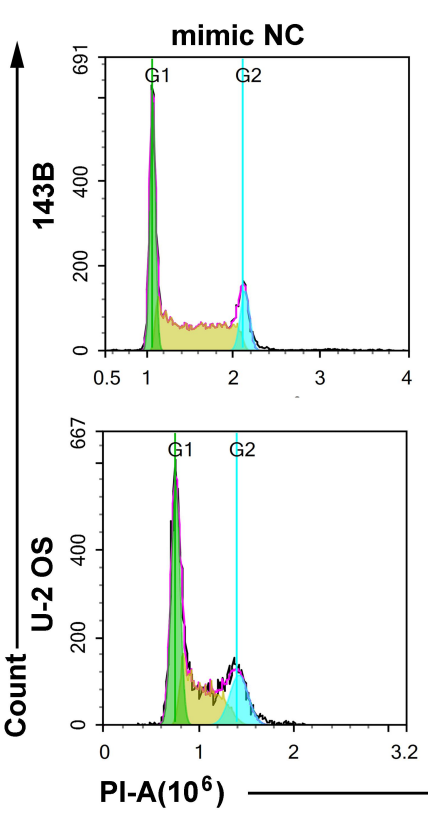

C

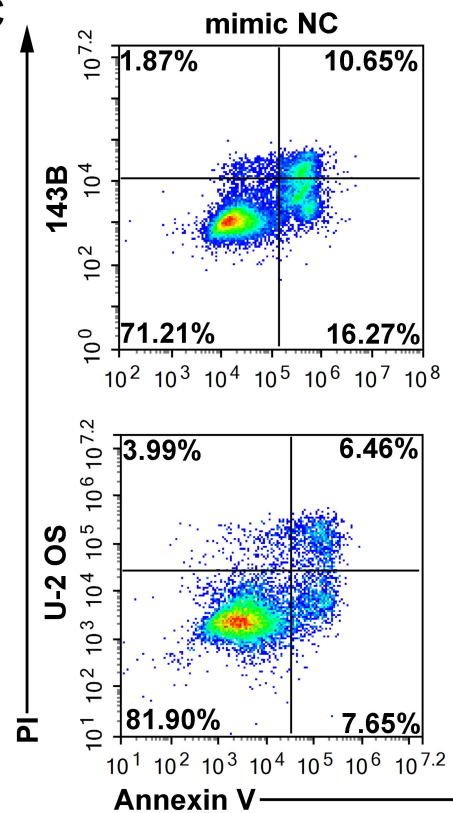

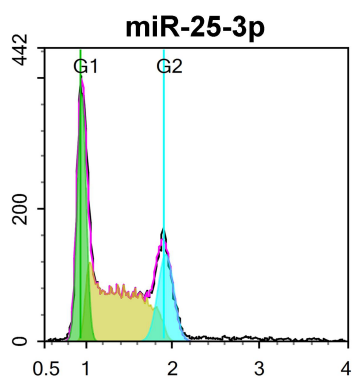
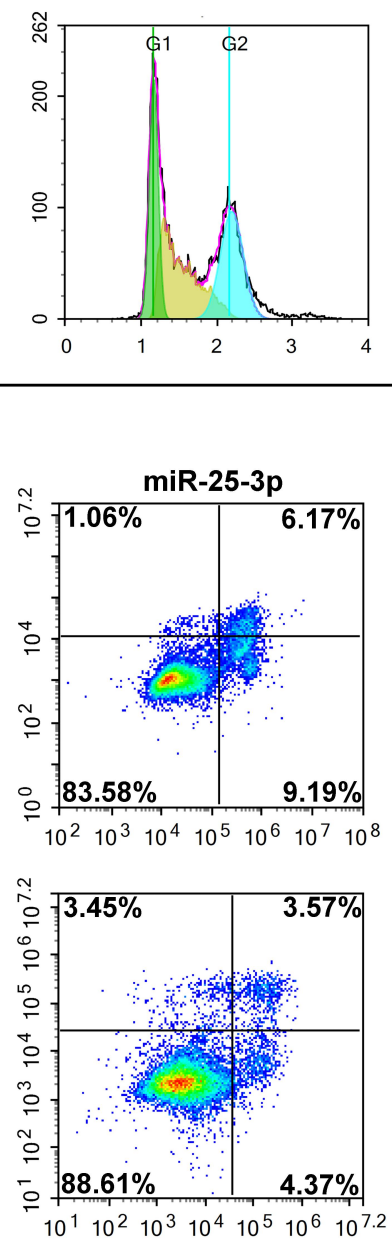
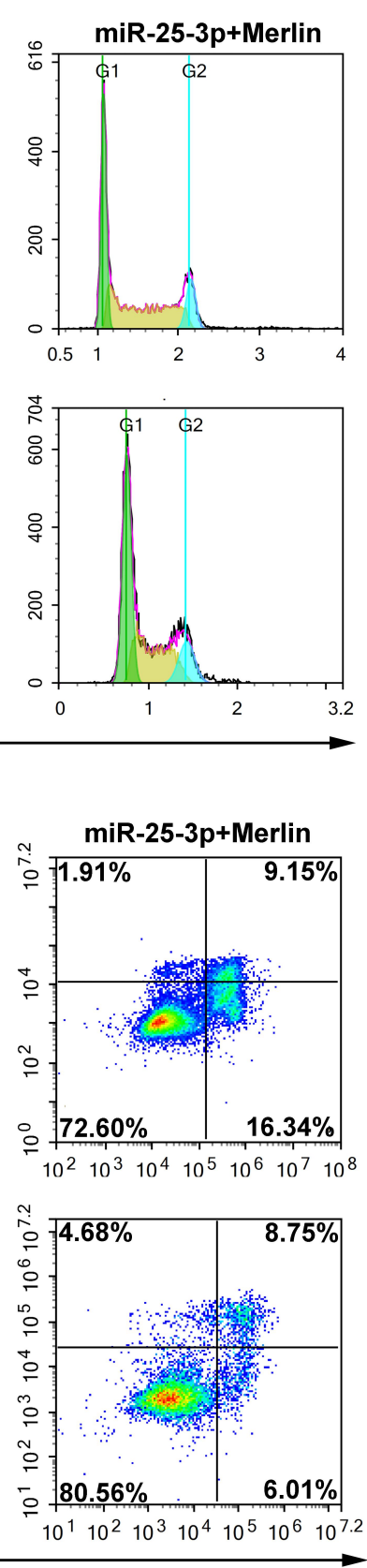

B
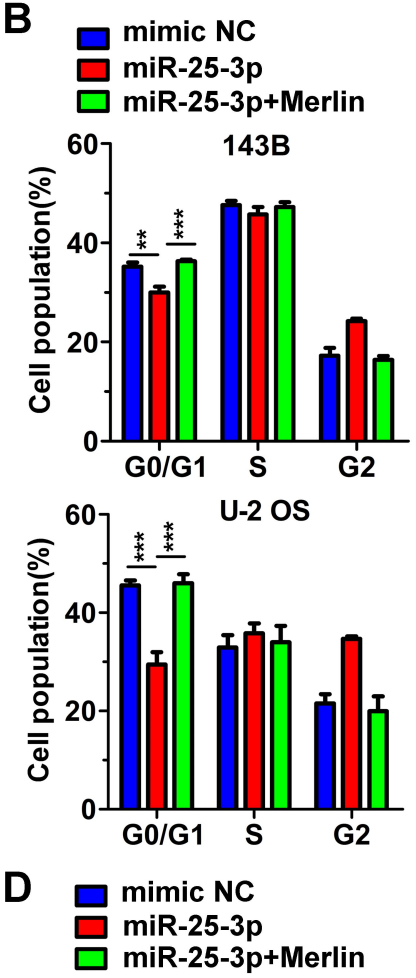

143B
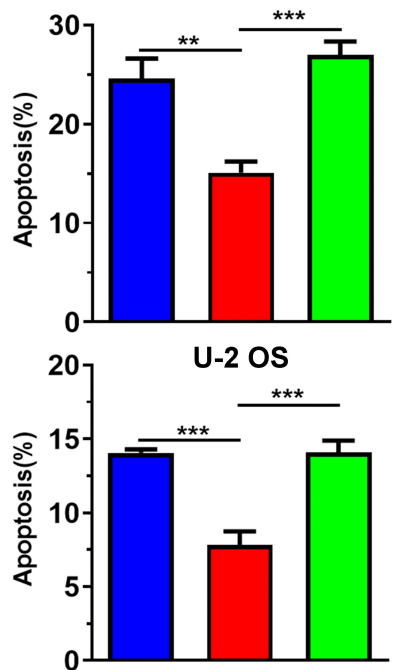

Figure 4 Cell cycle and apoptosis assay using flow cytometry. (A) Representative images of cell cycle analysis. (B) MiR-25-3p improves cell proliferation by inducing entry into the $\mathrm{S}$ phase. The data are expressed in terms of mean \pm s.d. of data from triplicate wells. $* * p<0.0 \mathrm{I}$, $* * * p<0.00 \mathrm{I}$. (C) Representative images of apoptosis analysis. (D) MiR-25-3p inhibited the apoptosis of osteosarcomatous cells. The data are expressed in terms of mean \pm s.d. of data from triplicate wells. $* * p<0.0 \mathrm{I}$, *** $p<0.00 \mathrm{I}$.

\section{Discussion}

OS is the second leading cause of cancer-associated mortality among young individuals worldwide, ${ }^{3-5}$ however, the underlying mechanism that modulates its occurrence and pathophysiology remains unclear. Merlin has been identified as an anti-oncogene $\mathrm{e}^{31,32}$ and plays an essential role in OS. MiRNAs are composed of ${ }^{17,20-22}$ nucleotides and exhibit either anti-oncogenic or oncogenic properties based on the characteristics of their targeting genes. ${ }^{14,33}$ The levels of miR-25-3p in carcinoma tissues and sera of patients with OS is higher than those in normal people. Several studies have shown that miR-25-3p promotes the progression of cancers such as triple negative breast cancer, cervical cancer, and gastric cancer. ${ }^{34-36}$ However, whether miR-25-3p targets Merlin and also acts as an oncogenic miRNA in OS remained unclear in earlier studies. In this study, we 
A

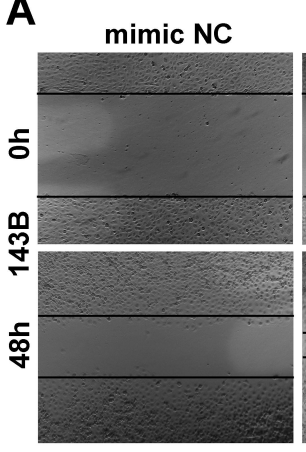

miR-25-3p
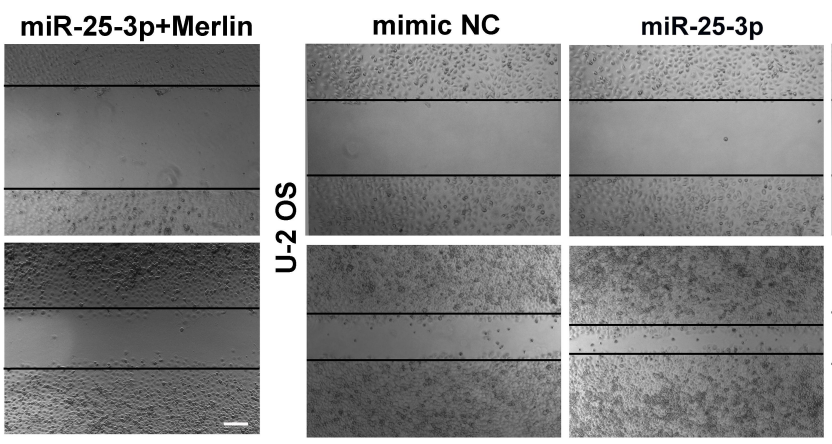

miR-25-3p+Merlin
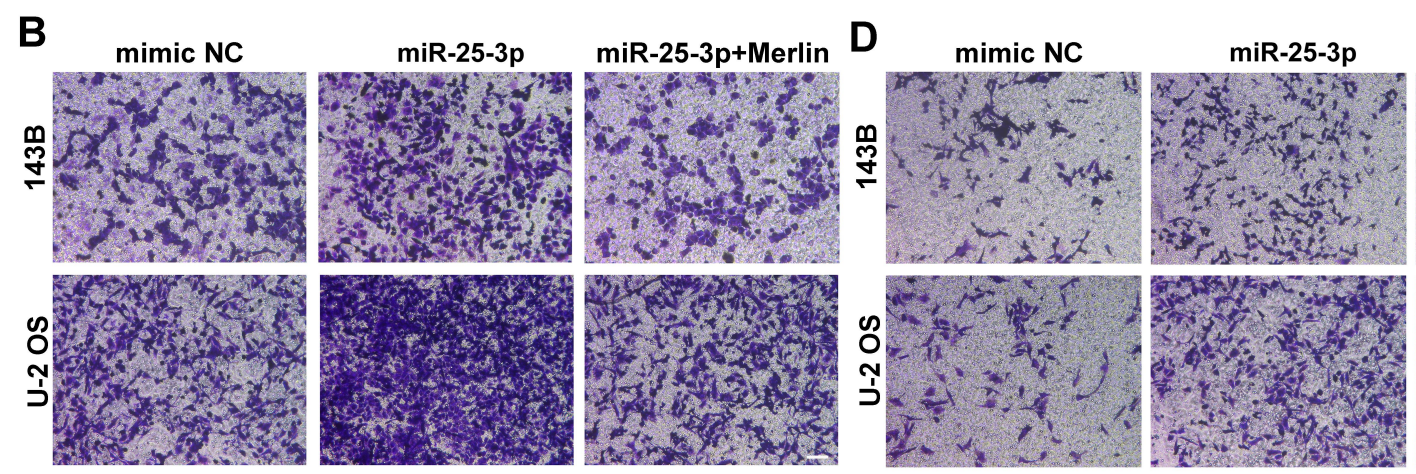

C

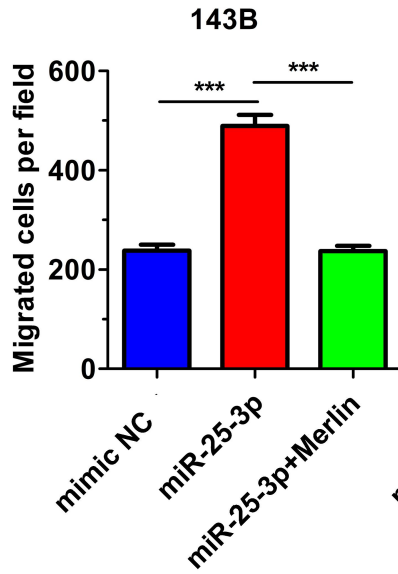

U-2 OS
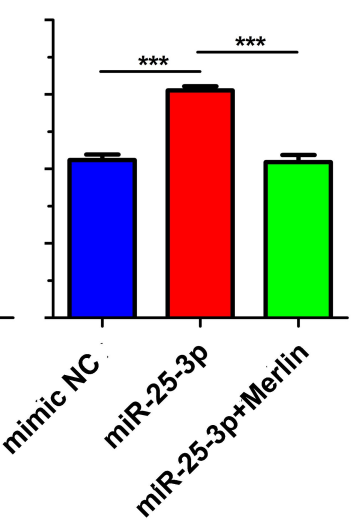

$\mathbf{E}$

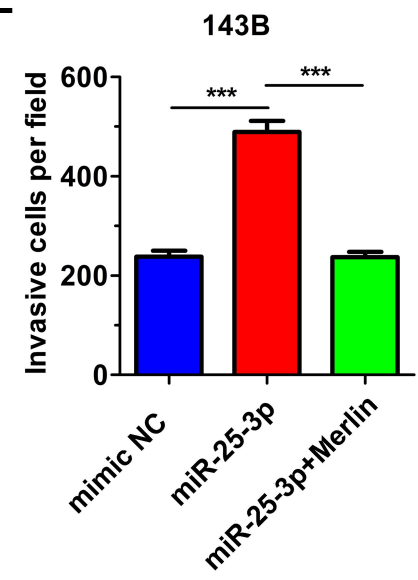

miR-25-3p+Merlin
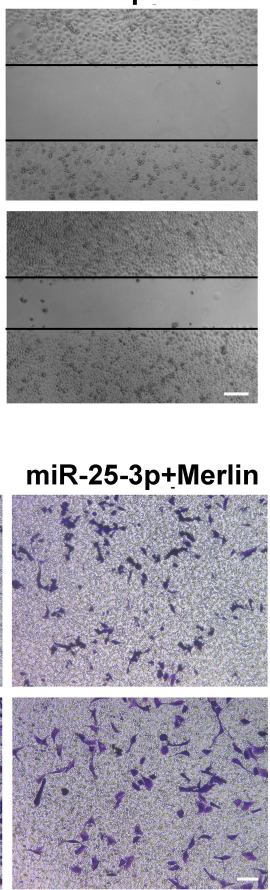

U-2 OS
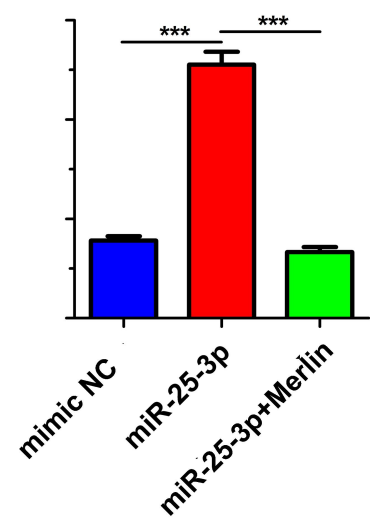

Figure 5 MiR-25-3p suppresses cell migration and invasion. (A) Wound healing assay. Bars, $200 \mu m$. (B) Representative images of the transwell migration assay. (C) Histogram representing number of migrated cells per field. The data are expressed in terms of mean \pm s.d. of data from triplicate wells. *** $p<0.0$ I. (D) Representative images of the Matrigel invasion assay. Bars, $200 \mu \mathrm{m}$. (E) Histogram representing the number of invasive cells per field. The data are expressed in terms of mean \pm s.d. of data from triplicate wells. $* * * p<0.01$.

revealed that miR-25-3p directly targets Merlin and downregulates its mRNA and protein expression. Moreover, our data revealed that miR-25-3p promotes cell proliferation, migration, and invasion, while it suppresses cell apoptosis, which suggests that miR-25-3p acts as an oncogenic miRNA that targets Merlin expression.

Although we have demonstrated that miR-25-3p is an oncogenic microRNA, the downstream molecules of miR25-3p/Merlin remain unexplored. It has been reported that Merlin is an upstream molecule of the Hippo pathway, which has recently emerged as a pathway associated with the control of cell growth and apoptosis. ${ }^{28-30}$ At the plasma membrane, Merlin recruits LATS kinases and coordinates their activation by Mst1, which induces the phosphorylation and subsequent activation of LATS1/2. ${ }^{11}$ Activated LATS1/2 inhibits YAP and TAZ activity by phosphorylating them. Eventually, phosphorylated YAP/TAZ fail to accumulate in the nucleus, which hinders their cotranscriptional activity. ${ }^{37}$ Merlin expression appears to be accompanied with high YAP phosphorylation. Moreover, 


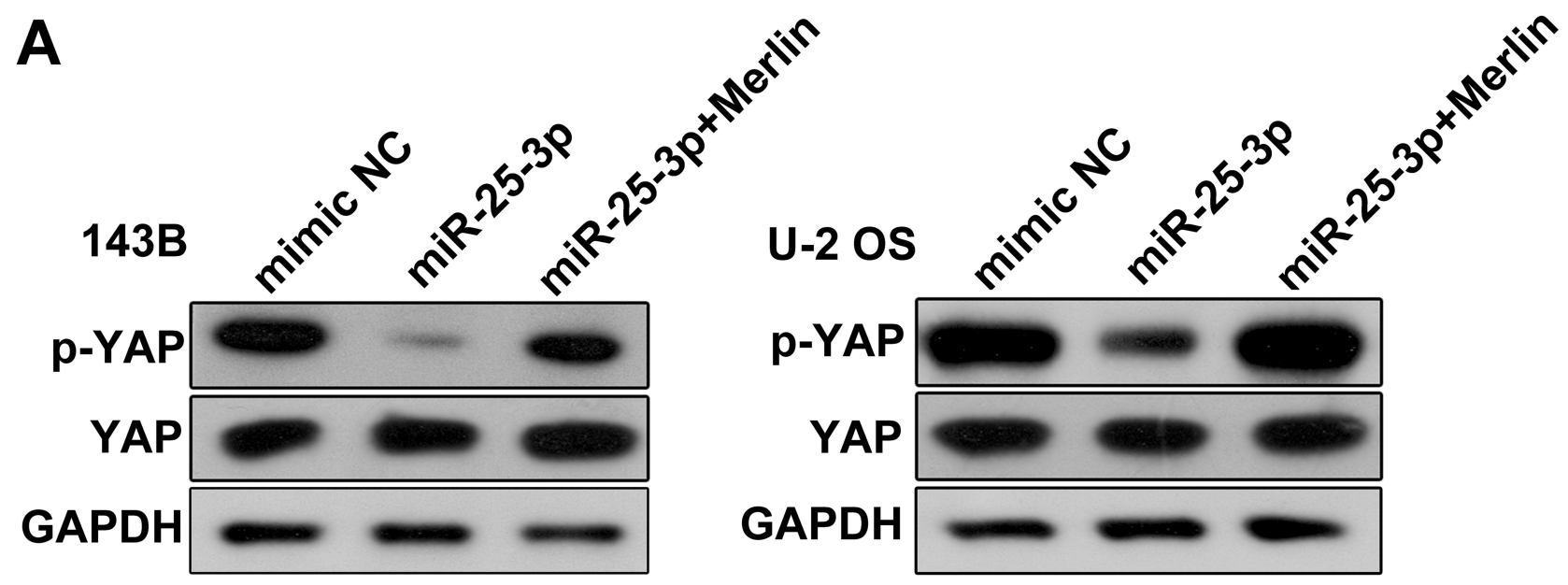

B
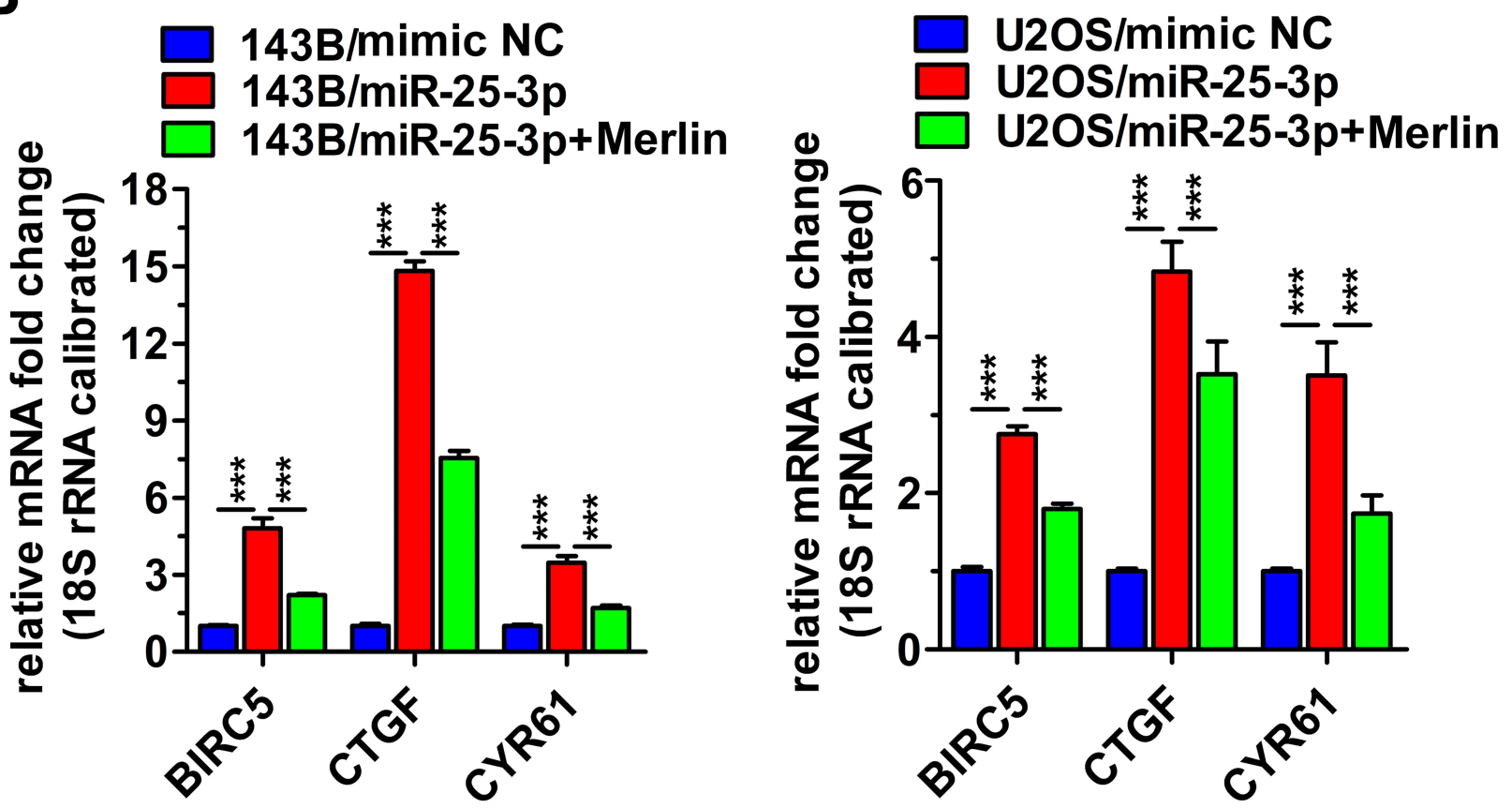

Figure 6 MiR-25-3p regulates the expression of downstream molecules in the Hippo pathway. (A) MiR-25-3p inhibited the phosphorylation of YAP. Western blot analysis was performed after a 48-h transfection period. Representative data from three independent experiments. (B) MiR-25-3p upregulates the mRNA expression of YAP target genes. RT-qPCR analysis was performed after a $24-\mathrm{h}$ transfection period. The data are expressed in terms of mean \pm s.d. of data from triplicate wells. $* * * p<0.0 \mathrm{l}$.

as shown by $\mathrm{Wu}$ et al, miR-25, the precursor of miR-25-3p, contributes to lung cancer cell proliferation and metastasis by targeting the LATS2/YAP signaling pathway. ${ }^{38}$ These findings indicate that miR-25-3p may regulate the Hippo pathway. Our study provided evidence that transfection with miR-25-3p reduced the levels of phosphorylated YAP in 143B and U-2 OS cells (Figure 6A), which consequently facilitated the entry of YAP into the nucleus and activated the transcription of YAP-targeting genes such as BIRC5, CTGF, and CYR61 (Figure 6B), which are common oncogenes. ${ }^{22-24}$ These findings suggest that miR-25-
$3 p$ exerts its oncogenic activity via the Hippo pathway. The process is outlined in Figure 7. In addition, Feng et al reported that miR-25 promotes the proliferation and motility of ovarian cancer cells by directly targeting LATS2. ${ }^{39}$ Therefore, miR-25-3p may regulate the Hippo pathway by downregulating Merlin and LATS2. However, further confirmation is required. We aim to determine whether the overexpression of $\mathrm{miR}-25-3 p$ can reverse the effects exerted by Hippo pathway inhibitors such as YAP-TEAD Inhibitor 1 (Peptide 17), which inhibit the binding of YAP/ TAZ to the transcription factor TEAD. 


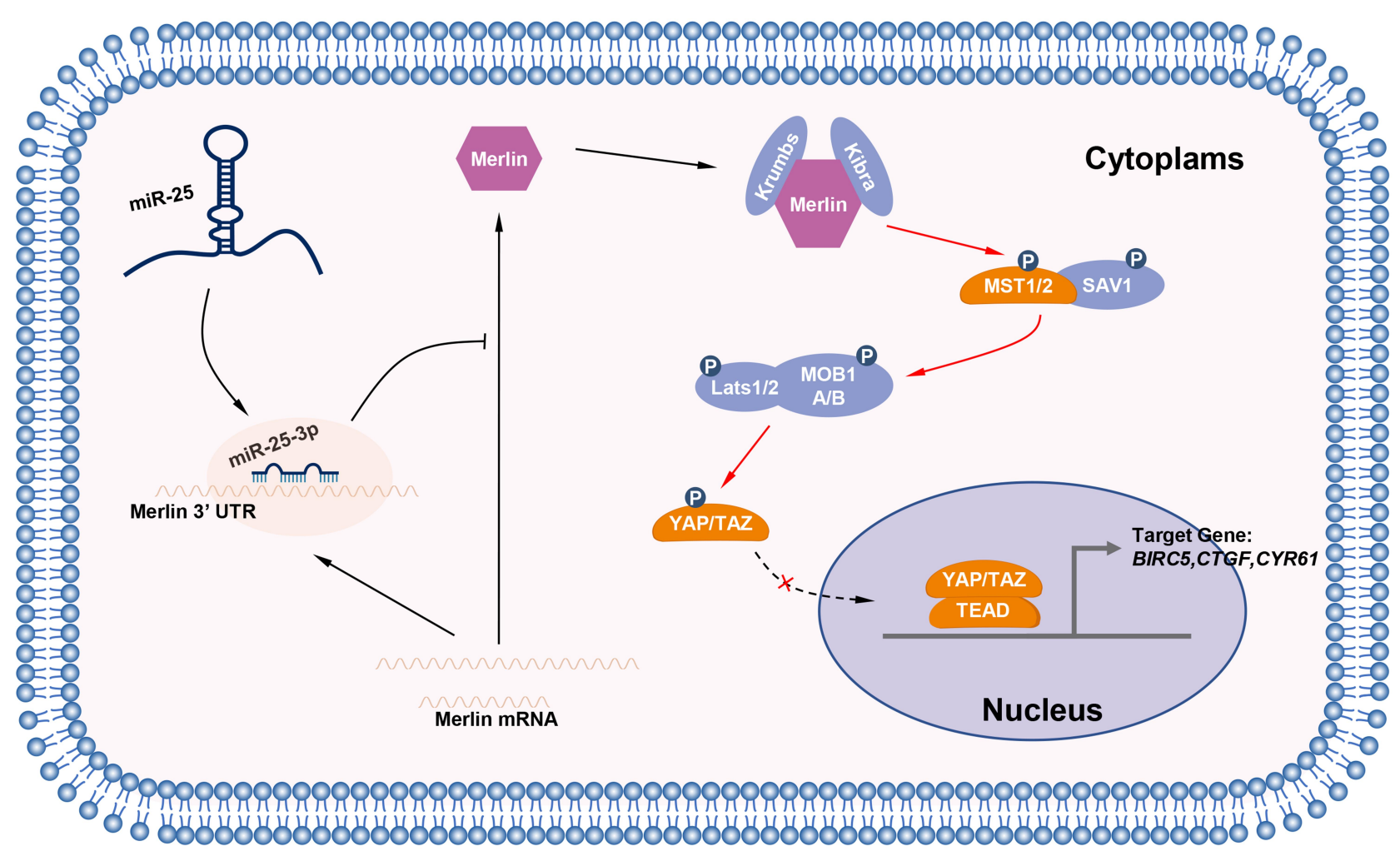

Figure 7 The diagrammatic sketch of the regulation of the Hippo pathway by miR-25-3p by targeting Merlin.

A miRNA can target numerous genes. Several targets of miR-25-3p have been reported, including, inter alia, BTG2, KLF2, and KLF4. miR-25-3p promotes cell proliferation and metastasis by regulating these genes. ${ }^{36,40} \mathrm{We}$ propose that miR-25-3p exerts its effects through the regulation of Merlin expression as well as by other means.

In conclusion, our results support the existence of the miR-25-3p/Merlin/YAP pathway. MiR-25-3p serves as an oncogenic microRNA in OS by downregulating Merlin. Our findings could lead to the development of novel drug targets for OS treatment.

\section{Data Sharing Statement}

The datasets used and/or analyzed during the current study are available from the corresponding authors upon reasonable request.

\section{Author Contributions}

All authors made a significant contribution to the work reported, whether that is in the conception, study design, execution, acquisition of data, analysis and interpretation, or in all these areas; took part in drafting, revising or critically reviewing the article; gave final approval of the version to be published; have agreed on the journal to which the article has been submitted; and agree to be accountable for all aspects of the work.

\section{Funding}

This work was supported by the National Natural Science Foundation of China (21307034), Natural Science Foundation of Fujian Province of China (2016Y0063) and Promotion Program for Young and Middle-aged Teacher in Science and Technology Research of Huaqiao University (ZQN-PY319, ZQN-PY419).

\section{Disclosure}

The authors declare that they have no conflicts of interest for this work.

\section{References}

1. Glover J, Fau KM, Tello T, et al. A summary of the osteosarcoma banking efforts: a report from the children's oncology group and the quadw foundation. Pediatr Blood Cancer. 2015;15455017(Electronic).

2. Grignani G, Palmerini E, Ferraresi V, et al. Sorafenib and everolimus for patients with unresectable high-grade osteosarcoma progressing after standard treatment: a non-randomised Phase 2 clinical trial. Lancet Oncol. 2015;14745488(Electronic).

3. Daw NC, Chou AJ, Jaffe N, et al. Recurrent osteosarcoma with a single pulmonary metastasis: a multi-institutional review. $\mathrm{Br}$ J Cancer. 2015;15321827(Electronic). 
4. Di Fiore R, Fau GA, Puleio R, et al. Modeling human osteosarcoma in mice through $3 \mathrm{AB}-\mathrm{OS}$ cancer stem cell xenografts. $J$ Cell Biochem. 2012;10974644(Electronic).

5. Moreno F, Cacciavillano W, Cipolla M, et al. Childhood osteosarcoma: incidence and survival in argentina. report from the national pediatric cancer registry, ROHA network 20002013. Pediatr Blood Cancer. 2017;1545-5017(Electronic).

6. Durnali A, Fau AN, Cangur S, et al. Prognostic factors for teenage and adult patients with high-grade osteosarcoma: an analysis of 240 patients. Med Oncol. 2013;1559-131X((Electronic)).

7. Osborne TS, Khanna C. A review of the association between osteosarcoma metastasis and protein translation. J Comp Pathol. 2012;1532-3129((Electronic)).

8. Petrilli AM, Fernandez-Valle C. Role of Merlin/NF2 inactivation in tumor biology. Oncogene. 2016;1476-5594((Electronic)).

9. Evans DG. Neurofibromatosis 2 [Bilateral acoustic neurofibromatosis, central neurofibromatosis, NF2, neurofibromatosis type II]. Genet Med. 2009;1530-0366(Electronic).

10. YA-Ohoo C, Groth S, Troutman S, et al. The NF2 tumor suppressor merlin interacts with Ras and RasGAP, which may modulate Ras signaling. Oncogene. 2019;1476-5594((Electronic)).

11. Cooper J, Giancotti FG. Molecular insights into NF2/Merlin tumor suppressor function. FEBS Lett. 2014;1873-3468(Electronic)

12. Hamaratoglu F, Fau WM, Kango-Singh M, et al. The tumour-suppressor genes NF2/Merlin and expanded act through hippo signalling to regulate cell proliferation and apoptosis. Nat Cell Biol. 2006;1465-7392(Print).

13. Horiguchi A, Fau ZR, Shen R, Fau SR, DM N, DM N. Inactivation of the NF2 tumor suppressor protein merlin in DU145 prostate cancer cells. Prostate. 2008;0270-4137(Print).

14. Nohata N, Fau HT, Kikkawa N, et al. Caveolin-1 mediates tumor cell migration and invasion and its regulation by miR-133a in head and neck squamous cell carcinoma. Int J Oncol. 2011;1791-2423 (Electronic).

15. Fan H, Lu S, Wang S, Zhang S. Identification of critical genes associated with human osteosarcoma metastasis based on integrated gene expression profiling. Mol Med Rep. 2019;20(2):915-930.

16. Gulino R, Forte S, Parenti R, Memeo L, Gulisano M. MicroRNA and pediatric tumors: future perspectives. Acta Histochem. 2015;117 (45):339-354.

17. Zhao B, Tumaneng K, Guan KL. The Hippo pathway in organ size control, tissue regeneration and stem cell self-renewal. Nat Cell Biol. 2011;13(8):877-883.

18. Fujiwara T, Uotani K, Yoshida A, et al. Clinical significance of circulating miR-25-3p as a novel diagnostic and prognostic biomarker in osteosarcoma. Oncotarget. 2017;8(20):33375-33392.

19. Yoshida A, Fujiwara T, Uotani K, et al. Clinical and functional significance of intracellular and extracellular microRNA-25-3p in osteosarcoma. Acta Med Okayama. 2018;72(2):165-174.

20. Pan D. The hippo signaling pathway in development and cancer. Dev Cell. 2010;19(4):491-505.

21. Zanconato F, Cordenonsi M, Piccolo S. YAP/TAZ at the roots of cancer. Cancer Cell. 2016;29(6):783-803.
22. Zhang H, Geng D, Gao J, et al. Expression and significance of Hippo/ YAP signaling in glioma progression. Tumour Biol. 2016.

23. Lai D, Ho KC, Hao Y, Yang X. Taxol resistance in breast cancer cells is mediated by the hippo pathway component TAZ and its downstream transcriptional targets Cyr61 and CTGF. Cancer Res. 2011;71 (7):2728-2738

24. Fan S, Liang Z, Gao Z, et al. Identification of the key genes and pathways in prostate cancer. Oncol Lett. 2018;16(5):6663-6669.

25. Li W, Cooper J, Zhou L, et al. Merlin/NF2 loss-driven tumorigenesis linked to CRL4(DCAF1)-mediated inhibition of the hippo pathway kinases Lats1 and 2 in the nucleus. Cancer Cell. 2014;26(1):48-60.

26. Rausch V, Hansen CG. The hippo pathway, YAP/TAZ, and the plasma membrane. Trends Cell Biol. 2020;30(1):32-48.

27. Li Y, Zhou H, Li F, et al. Angiomotin binding-induced activation of Merlin/NF2 in the Hippo pathway. Cell Res. 2015;25(7):801-817.

28. Cao J, Huang W. Two faces of Hippo: activate or suppress the Hippo pathway in cancer. Anticancer Drugs. 2017;1473-5741(Electronic).

29. Felley-Bosco E, Stahel R. Hippo/YAP pathway for targeted therapy. Translational Lung Cancer Res. 2014;3(2):75-83.

30. Song Y, Fu J, Zhou M, et al. Activated hippo/yes-associated protein pathway promotes cell proliferation and anti-apoptosis in endometrial stromal cells of endometriosis. J Clin Endocrinol Metab. 2016;101 (4):1552-1561.

31. Lee JY, Fau KH, Ryu CH, et al. Merlin, a tumor suppressor, interacts with transactivation-responsive RNA-binding protein and inhibits its oncogenic activity. J Biol Chem. 2004;0021-9258(Print).

32. Li W, Fau CJ, Karajannis MA, Fau KM, Giancotti FG, Giancotti FG. Merlin: a tumour suppressor with functions at the cell cortex and in the nucleus. EMBO Rep. 2012;1469-3178(Electronic).

33. Wang W, Luo Y-P. MicroRNAs in breast cancer: oncogene and tumor suppressors with clinical potential. J Zhejiang Univ Sci B. 2015;16 (1):18-31.

34. Ning L, Zhang M, Zhu Q, Hao F, Shen W, Chen D. miR-25-3p inhibition impairs tumorigenesis and invasion in gastric cancer cells in vitro and in vivo. Bioengineered. 2020;11(1):81-90.

35. Song J, Li Y. miR-25-3p reverses epithelial-mesenchymal transition via targeting Sema4C in cisplatin-resistance cervical cancer cells. Cancer Sci. 2017;108(1):23-31.

36. Chen H, Pan H, Qian Y, Zhou W, Liu X. MiR-25-3p promotes the proliferation of triple negative breast cancer by targeting BTG2. Mol Cancer. 2018;17(1):4.

37. Yin F, Fau YJ, Zheng Y, et al. Spatial organization of Hippo signaling at the plasma membrane mediated by the tumor suppressor Merlin/ NF2. Cell. 2013;1097-4172(Electronic).

38. Wu T, Hu H, Zhang $\mathrm{T}$, et al. miR-25 promotes cell proliferation, migration, and invasion of non-small-cell lung cancer by targeting the LATS2/YAP signaling pathway. Oxid Med Cell Longev. 2019;2019:9719723.

39. Feng S, Pan W, Jin Y, Zheng J. MiR-25 promotes ovarian cancer proliferation and motility by targeting LATS2. Tumour Biol. 2014;35 (12):12339-12344.

40. Zeng Z, Li Y, Pan Y, et al. Cancer-derived exosomal miR-25-3p promotes pre-metastatic niche formation by inducing vascular permeability and angiogenesis. Nat Commun. 2018;9(1):5395.
Cancer Management and Research is an international, peer-reviewed open access journal focusing on cancer research and the optimal use of preventative and integrated treatment interventions to achieve improved outcomes, enhanced survival and quality of life for the cancer patient
The manuscript management system is completely online and includes a very quick and fair peer-review system, which is all easy to use. Visit http://www.dovepress.com/testimonials.php to read real quotes from published authors. 